TITLE:

\title{
Children in a Rail-Based Developed Area of Japan
}

$\operatorname{AUTHOR}(\mathrm{S})$ :

Waygood, E. Owen D.; Kitamura, Ryuichi

CITATION:

Waygood, E. Owen D....[et al]. Children in a Rail-Based Developed Area of Japan.

Transportation Research Record: Journal of the Transportation Research Board 2009,

2125: $36-43$

ISSUE DATE:

2009-12-01

URL:

http://hdl.handle.net/2433/128871

\section{RIGHT:}

(C) 2010 National Academy of Sciences; This is not the published

version. Please cite only the published version.; この論文は出版社版で ありません。引用の際には出版社版をご確認ご利用ください。 


\section{CHILDREN IN A RAIL-BASED DEVELOPED AREA OF JAPAN: TRAVEL PATTERNS, INDEPENDENCE, AND EXERCISE}

E. Owen D. Waygood*

Department of Urban Management Kyoto University

C Cluster, Katsura Campus

Nishikyo-ku, Kyoto, Japan

P: $+81-75-383-3242$

F: $+81-75-383-3236$

E: owen@trans.kuciv.kyoto-u.ac.jp

Ryuichi Kitamura

Department of Urban Management

Kyoto University

C Cluster, Katsura Campus

Nishikyo-ku, Kyoto, Japan

P: $+81-75-383-3238$

F: +81-75-383-3241

E: rkitamura@trans.kuciv.kyoto-u.ac.jp

*Corresponding author

July 28, 2008

Word Count: $4650+5$ figures +3 tables $=6650$ 


\begin{abstract}
This paper examines measures of travel behavior and exercise for children in four different levels of population density in the Osaka Metropolitan areas of Japan. This area's built environment reflects principles of Transit Oriented Development with neighborhoods that have grown around an initial train station, where shops intermix with housing and often cluster around the station. Local trips by adults are often by non-motorized modes. With respect to children's travel behavior, this study looked at measures of social cohesion, independent travel, mode splits, and average travel times. It found positive correlations between population density with both the social cohesion measure and the percent of independent trips over a day. Negative correlation was observed for travel time. The measures for exercise were the number of times a child participated in running-level activities over a day and how much exercise was gained through non-motorized travel. Mixed results occurred with only Sundays having a negative correlation for the running-level activity participation and the correlation for the amount of exercise gained through non-motorized travel flip-flopping between weekdays and Sundays.
\end{abstract}




\section{INTRODUCTION}

Higher density and mixed land-use development has the potential to make transportation more sustainable by reducing the distances to stores and services $(l)$ and through mass transit's economies of scale (2). However, increased economic pressure on land-use may inadvertently reduce open-space for children to play and exercise. Parents consider many things when choosing where to live and raise their children, but factors such as reduced chauffeuring and increased community cohesion have been cited as desirable qualities of a built environment (3). This paper will look at these issues across four population density groups for mixed land-use built environments in Japan by comparing minors' trips with respect to mode splits and distance (environmental), average trip duration (convenience and time burden), seeing known people while traveling (community cohesion), rate of independent trips (reduced chauffeuring burden), and two exercise related measurements (health).

In order to reduce the impact from private vehicle externalities, development patterns such as Transit Oriented Development (TOD) that support walking and cycling for local trips and mass transit for longer trips are proposed as a possible solution. TOD centers around a transit node, and encourages mixed land-use to reduce distances to stores and services making non-motorized modes more appealing. Bonner's (3) results concerning reduced chauffeuring and increased community cohesion may be valid when comparing rural areas to zoned urban development, but urban built environments with TOD properties may have not have the same results. Recent years have seen increased motorization in Japan, but little attention has been paid to what impacts this may have on children.

Bonner summarized the benefits that people felt a rural setting had over an urban for raising children as: greater community cohesion that reduces anxiety; shorter distances to destinations that reduce chauffeuring time; and the combination of greater community cohesion and shorter distances that makes children's autonomous travel possible by reducing parents' anxiety. However, those perceived differences between rural and urban areas may be exacerbated by zoning which segregates land use into residential, commercial, and industrial zones. Mixed land-use may retain some of the benefits of a village where shops and services are on a local level, so that trip distances are reduced. Further, an increase in population density can result in greater service density, potentially further reducing travel distance. If a significant amount of travel is local, the potential for interaction with one's neighbors could also increase, adding to community cohesion. Studying the three factors cited by Bonner in mixed land-use areas may prove to have different results than those perceived in Canada where zoning is practiced. The built environment of the study area has mixed land-use areas from low to high density and thus can potentially highlight such differences between distance, duration, chauffeuring, community cohesion, and independent travel.

A further issue is that in North America there are increasing concerns about an increase in the number of overweight children $(4,5)$, and has reached the news in Japan (6). One aspect of this problem is likely diet (7), but no matter the diet, exercise is an important aspect of a healthy lifestyle and children in Canada are leading increasingly sedentary lifestyles (8). Increasing population density to support mass transit without proper consideration to children's needs may inadvertently reduce physical exercise if parks or sports facilities are not available for intense exercise, such as running, which has been recommended by health researchers for improving health (9). For planners, knowing where children participate in "running-level" activities should be valuable. A potential downside of increased density may be reduced space for such activities to occur.

Open spaces are likely important for "running-level" activities, but, with TOD development more trips may be by foot or bicycle, which are forms of exercise An increase in population density may increase the chance that destinations, such as friends or stores, will be near-by. Thus, with an increase in population density walking and cycling trips may increase as distance becomes less of a factor. Assuming that that is true, there should be a greater share of trips that are by foot or bicycle with increasing population density. This can potentially increase the amount of exercise that a child gains through travel, but shorter distances could possibly negate that benefit. With respect to recommended levels of exercise, Armstrong (10) determined after a review of research that exercise of 20 minutes or greater, three times a week that involved major muscle groups and brought heart rates up to 140 beats per minute (bpm) was advised. He also noted that children walking at $6 \mathrm{~km} /$ hour $(3.7 \mathrm{mph}$ ) reached heart rates of $140 \mathrm{bpm}$. Although the children may not always reach such speeds, the amount of exercise that is achieved through travel by foot or bicycle may be an important 
consideration in overall benefits of TOD development. It is important to understand how children in high density built environments are affected with respect to exercise. Therefore, along with the number of times that children do "running-level" exercise in a population density group, the amount of exercise achieved over a day through travel by foot or bicycle is also considered.

To sum up, there are potentially different realities of zoned and mixed land-use development with respect to children's travel. TOD development may offer greater opportunity to travel by non-motorized means or mass transit for adults, but questions about community cohesion and children's independent travel exist. Further, lower density that allows for more open space may increase physically active play, but children in TOD development with higher population densities may achieve a daily base of exercise through physically active modes of transport such as walking or cycling. The Kei-Han-Shin area of Japan offers an interesting contrast to the zoned development of Canada and other such countries. Although the cultures obviously differ, the differences across the four population density groups will show the potential of TOD to increase sustainable travel, while also considering health impacts.

\section{STUDY AREA AND EXPECTIONS}

Urban development in the Kei-Han-Shin area (abbreviation for Kyoto-Osaka-Kobe) of Japan that encompasses Osaka, Kobe and Kyoto exemplifies TOD recommendations. Mixed land-use is prevalent, and shops and residences increase in density near train stations. There was a population of 18.2 million in 2002 and an average household car ownership of 0.97 , which is lower than the average of 1.32 in Japan. Within the area itself, household ownership varies from 0.5 in urban centers to 1.37 in emerging areas.

The household automobile ownership was high for the children's families in this study with respect to the above averages (Table 1), which can likely be explained by differences between household lifecycles, with families having higher automobile ownership. Despite the variation in automobile ownership, children in all areas from low (less than 2000 people $/ \mathrm{km}^{2}\left(5180 \mathrm{people} / \mathrm{m}^{2}\right)$ ) to very high (equal to or more than 6500 people $/ \mathrm{km}^{2}\left(16835\right.$ people $\left./ \mathrm{m}^{2}\right)$ ) population density in the Kei-Han-Shin area displayed higher levels of independent travel (11) than in the US (12) or Calgary, Canada (13).

Osaka and Kyoto are two of Japan's major cities from before the $19^{\text {th }}$ century. Both cities have grown and expanded over the last century with rail-based communities. Private rail and land development companies focused on developing suburban communities around their lines (13). This in combination with lax zoning that allows even small industries in the strictest residential zones (14) has created a built environment indicative of TOD principles. Therefore, results from this study are reflective of children's travel behavior in such development.

Waygood and Kitamura (11) found that minors' trip distance and trips after 8 pm were negatively associated with independent trips, but that seeing a known person while traveling between the origin and the destination was positively associated with an increase in the percentage of independent trips over a day. In mixed land-use areas, shops and services may be closer with increasing population density and those local trips could increase community cohesion in the area. Thus, the expectation is that with increasing population density there will be shorter average trip duration, an increased percentage of trips where a known person is seen during travel, and an increased percentage of trips that are independent.

With respect to exercise, the number of times that the children participate in "running-level" exercise and where that occurs will be compared across population densities. It is anticipated that exercise for children in higher density areas will occur at public open-spaces rather than at home due to space restrictions. Although recent suburban homes may incorporate a small yard, family residences in more urban areas typically do not have yards where play is possible.

The amount of exercise gained through travel by foot or bicycle depends both on the likelihood of those modes being used, but also the distance traveled. It is expected that children in higher density areas go by foot or bicycle more often as distances are likely shorter to destinations, but the duration of such trips may be quite short. It is not clear which population density group will get the greatest amount of exercise through walking and cycling, but it is expected that the frequency of such trips in high density areas will be greater than in lower density areas, so that the higher density will achieve greater daily averages, despite potentially shorter duration of trips. 


\section{STUDY DESCRIPTION}

The data for this study comes from travel diaries completed by grade five students at five different schools in the Kei-Han-Shin area between July, 2007 and January, 2008. One of the goals of those travel diaries was to examine independent travel (12), so a travel diary was developed for children to complete themselves. Figure 1 shows an example sheet for one trip. Each trip during the day was entered on a separate sheet of paper in a travel diary of eight pages. Additional pages were available through the teacher if needed.

Due to cultural reasons the principal author and the study were introduced through an intermediary to schools interested in participating. Grade-five students were chosen for two main reasons: the teachers at the schools felt that they were mature enough to participate; and the study fit into current courses about the environment.

To increase the accuracy of responses, the author and other research students from Kyoto University went to the schools and gave presentations on how to complete the diaries. They worked with the children to complete the previous day's information to ensure that they understood how to correctly fill in the dairies. All schools completed information for a Sunday and one weekday between Monday and Thursday.

The five schools that participated were from distinctly different areas. One school had a low population density and was in an agricultural area. A second school was from a town of 16,500 people. A third school was in a higher density city area $\left(6,080\right.$ people $/ \mathrm{km}^{2}\left(15,747\right.$ people $\left.\left./ \mathrm{m}^{2}\right)\right)$. A fourth school was from an old city with high density $\left(10,670\right.$ people $/ \mathrm{km}^{2}\left(27,600\right.$ people $\left.\left./ \mathrm{m}^{2}\right)\right)$. The last school drew its students from the southern part of its prefecture and students came from a range of population densities. The population density groups were determined by the four local schools and then the children from the last school, a competitive school, were assigned appropriately. Some basic characteristics of each population density group can be seen in Table 1 . The percent of boys is higher in the low density areas which may increase independence levels (16).

\section{Exercise}

This study looked at the occurrence of "running-level" activities. The children themselves determined and reported the physical intensity of activities. On the travel diary (Fig. 1) the children indicated what kind of activities they engaged in: "sitting/standing-level", "walking-level", or "running-level." Children were instructed that activities such as swimming or hiking were "running-level."

The methods used to measure exercise here were simple. They were not meant as definitive measurements of the amount of exercise that the children attained. The purpose was to get an overview of exercise achieved through walking and cycling along with the occurrence of "running-level" activities. In order to determine actual health benefits, it would be necessary to use pedometers or heart-rate meters. However, it was the possibility of such exercise and the location that were primarily of interest for "running-level" exercise, so the methods used were considered sufficient.

\section{VARIABLES IN THE ANALYSIS}

Analysis of variance (ANOVA) was used to compare the average rates across the four different population density groups and correlation coefficients were calculated using one-tailed bi-variate analysis. Each variable that was compared is explained below. Previous research into children's travel indicated that weekend travel and weekday travel differ $(13,15)$. Therefore, all analysis was done separately for weekdays and Sundays. There was insufficient data from Saturdays to use as only three of the five schools completed diaries for that day.

\section{Known Person Seen During Travel}

That "a known person was seen" applies to the case where the child indicated they saw someone that they knew, either another child or an adult, while traveling between their origin and destination. This variable is defined as the ratio of the number of trips over a day where the child indicated seeing someone they knew, divided by all trips during that day by the same child.

\section{Independent Trips}


This variable is the percentage of all trips over a day that was independent of an adult. If an adult accompanied the child on any segment of the trip (such as to the train station), the trip was deemed to be accompanied and not independent. A trip with friends or siblings was independent if no adult was indicated as a companion.

\section{Running-Level Activities}

The number of trips where the child indicated that there was a "running-level" activity at the destination was tabulated for the day. Although it is possible to determine the length of time a child was at the destination, it would not be accurate to assume that they were running the entire time, so the duration at the destination could not be used as a measure. The children could indicate that more than one level of physical activity occurred at the destination.

\section{Exercise Through Travel}

The amount of exercise gained through travel was a sum of all minutes traveled by foot or bicycle. Each trip was broken into separate segments for each mode and the duration recorded. For example, a trip where the child walked to a train station, rode a train, then walked to their destination would have two separate segments with walking and one with train. The duration for the two walking segments would be summed and added to any other walking or cycling times over that day.

\section{Average Trip Duration}

This is an arithmetic average of the durations of all trips reported by each child.

\section{RESULTS AND DISCUSSION}

This study included different measurements related to travel and exercise. The analysis for weekdays will be presented first, followed by the results for Sundays. The first section will look at mode splits with respect to distance to highlight the impact of distance and density on mode selection. The following sections will then show the results of the ANOVA analysis and discuss them.

\section{Mode Splits}

Mode splits for all trips during a day can be seen in Figures 2 and 3 for weekdays and Sundays respectively. The graphs show the average number of trips that the children indicated were "near" or "far". The children indicated a trip was far if they felt they could not walk to the destination in 15 minutes. Mode splits are then shown within those divisions. Using these graphs, differences in number of "far" or "near" trips along with the mode split for each can be seen.

For weekdays, there are more "near" trips than "far" for each population density group, except for the lowest population density group. In all areas, the school trips were nearly $100 \%$ by foot, which accounts for walking trips being represented in far trips for the lower population density groups. All areas show some amount of car trips, but aside from the lowest population density group, it plays a minor role. For the higher density population density groups, mass transit plays a greater role in trips that were "far". This result supports the assertion that there would be an increase in near trips, both in absolute number and in proportion, facilitating walking and cycling with greater population density.

Sunday's mode split shown in Figure 3 shows a considerable difference from the weekday mode split. Sundays are typically a family day in Japan and families will often travel together, going shopping or to a restaurant. For the highest population density group there were more "near" trips than "far", whereas the lowest population density group had a considerably larger number of far trips than near ones. It is interesting to note that in the highest population density group that practically half of all far trips were still by non-motorized modes. It is also interesting that mass transit features more in the lower two population density groups, despite those areas having higher household vehicle ownership (Table 1). What this may show is that the lower population density groups must travel further to reach their destinations and that motorized modes, including mass transit, are necessary for such trips.

The results for both weekday and Sunday mode splits show a trend of decreasing car use with increasing population density that would support arguments that TOD can reduce car-use through changes to the built environment. 


\section{Analysis of Variance Results}

The following sections discuss the five separate ANOVA analyses on the variables described in the Analysis section. Tables 2 and 3 summarize the results of all five analyses for weekdays and Sundays respectively. The results for each distinct variable are then discussed separately. All the averages are statistically different ( $\mathrm{p}$ values $<0.001)$.

\section{Known Person Seen During Travel}

The first question investigated was how many trips there were where a known person was seen. This question was analyzed to test community cohesion across the population density groups. For weekdays (Table 2), there was little difference across the population density groups, but the greatest average percentage $(78.3 \%)$ of trips where a known person was seen occurred in the highest population density group and the smallest percentage $(64.3 \%)$ in the lowest population density group. There was not a consistent increase with population density, but there is a small correlation (0.135). For Sundays, the average percentage dropped considerably, with the lowest average percentage at $37.7 \%$ for the "high" population density group (4000 to 6499 people $/ \mathrm{km}^{2}$ ), but the greatest percentage was again in the highest population density group with an average $61.3 \%$ of all trips over a day where each child recorded a known person being seen. It is not clear why the "high" density group had the lowest average, as there were not a greater number of far trips (Figure 3) than the lower densities, nor a greater number of car trips, which could potentially lower a child's awareness of their surroundings. Although there was not a linear relationship, there was a low correlation (0.126) and the highest population density group had the greatest average percentage of trips where a known person was seen suggesting that high community cohesion is possible in extreme urban settings as well.

\section{Independent Trips}

The percentage of all trips that each child made over the day that were independent of an adult was compared across the density groups. On both weekdays and Sundays, there was a trend of increasing independence with population density, countering the perceptions of the parents in Bonner's study. There was medium correlation on weekdays (0.369) and low correlation on Sundays (0.226). The greatest change was between the two lowest population density groups on weekdays $(58.3 \%$ to $86.7 \%$ ), which may be explained by a greater number of far and car trips in the lowest population density group (Figure 2). The other major change was on Sundays between the two highest population density groups (30.4\% and 53.9\%) (Figure 3), where again a difference between the number of far trips and the number of cars trips was observed. These results suggest that local trips are an important aspect of greater independence for children.

\section{"Running-Level" Exercise}

For both weekday and Sundays, the lowest density group had the highest average participation in such activities. However, there was not a consistent trend with respect to population density and there was only low correlation observed on Sundays (-0.106) and no correlation on weekdays (-0.061). The highest population density had an average greater than once per day on both weekdays and Sundays, while the two middle groups fell below one on Sunday. This result suggests that very low densities allow for a greater amount of "running-level" exercise. The location of these activities is examined next.

The location of "running-level" activities can be seen in Figures 4 and 5 for a weekday and a Sunday respectively. For weekdays, all population density groups showed an average of at least one "running-level" activity over the day. The lowest population density group had a considerable number of "running-level" activities occurring at school. All the schools in the study had the same basic school grounds, but it may be that children played at school before heading home where distances to friends' homes may be considerable. The two higher population density groups showed more exercise occurring at parks, and the middle two population density groups show sports facilities being used.

For Sundays, the lowest population density group again had the highest number of times that "running-level" exercise occurred. Roughly $50 \%$ of all "running-level" activities occurred at a residence for the two lower population density groups. The two higher population density groups however showed greater use of sports facilities such as soccer fields or swimming pools. Park use was evident in all areas, but quite low in the "medium" population density group (2000-3999 people/km²). 
In the lowest population density group, a shopping center was a location for "running-level" exercise. There is a large chain-store mall near that area where a play area is located on the roof. This is a common feature of department stores and shopping malls in the Kei-Han-Shin area.

The results here suggest that with increasing population density, public facilities such as parks and sports grounds become increasingly important since less space is likely available for "running-level" play at home. The shopping center for the low density area may act as a gathering point where parents can shop and children can play.

\section{Exercise through Travel}

The amount of exercise gained purely through travel was examined. The total minutes of all trip segments over a day that were either walking or cycling were summed.

On weekdays the lower two densities got over 40 minutes through travel, with the higher two achieving 33.6 and 27.3 minutes respectively which has a low negative correlation $(-0.150)$. On Sundays, there is a reverse trend with an increase from 11.5 minutes in the lowest density group up to 23.7 minutes in the highest which has a low positive correlation (0.153). The amount of exercise on weekdays is quite high for the lower density groups as their school commutes are quite long. All students walked to school, with the lowest density group having a "group leader" type system where the older children (grades five and six) lead the younger children in a similar way to what is referred to in some literature as a "walking school bus" (16) except without an adult to guide them. The trend on Sundays is more what was expected for the differences across population densities, with the higher densities enabling more walking and cycling trips, thus obtaining more exercise that way. With the walk-to-school system all of the population density groups averaged more than the recommended 20 minutes of exercise (10) purely through travel.

\section{Average Travel Time}

The average travel time for each area was determined from all trips in the population density group. The average length of trips for weekdays was over 13 minutes for the two lower population density groups and less than 9 minutes for the two higher population density groups which has a low negative correlation (-0.233). Longer school trips would contribute to this difference. On Sundays, all population density groups were around 20 or 21 minutes except for the highest population density group, which was around 15 minutes and has a low negative correlation (-0.142). There were more near trips in the highest population density group, but there were also the lowest number of car trips. This would suggest that the advantages of having destinations close-by is greater than the speed advantage that cars have. This result was also evident in adult behavior in previous work done by Kitamura et al. (17), which showed that suburban area residents had longer average trip duration than urban area residents.

\section{CONCLUSIONS}

In this study, the impact of increasing population density in mixed land-use areas in the on travel behavior and exercise for children aged 10 and 11 was analyzed for heavily rail-developed Kei-Han-Shin area of Japan. The results suggest that an increase in population density can reduce average trip duration, impact community cohesion positively, and increase independent travel for minors. However, the lowest population density area had a higher average number of "running-level" activities than the other areas and the higher density areas showed greater use of public facilities that allow for such activities suggesting that attention must be paid to insuring that such facilities exist if population densities are increased. All of the population density groups on average got a considerable amount (more than 27 minutes/day) of exercise through travel during the week, but on a Sunday only the highest density area had more than 20 minutes of exercise achieved through travel over the day. The lowest population density area overcame the distance to commute to school with a "walking school bus" system that was lead by the older children (aged 10-12). The results of the study would be strengthened with an increase in the number of schools for each population density category.

Overall, the benefits of living in rural areas that Bonner concluded were not evident in the Kei-Han-Shin area of Japan. This was likely the result of mixed land-use development which allows a greater amount of daily activities to occur at local levels. The inconvenience of urban areas in Canada may be a result of zoning-based development which separates residential, commercial, and industrial 
uses. The empirical evidence from this study shows that urban centers can also have high levels of community cohesion evidenced through the high occurrences of children seeing people they knew while traveling to a destination. However, there was some evidence that children in the low density areas had a greater amount of "running-level" play and that this occurred at a residence. In higher density areas, it may not be possible for such activities to occur within the boundaries of the residence, and greater care by planners to incorporate local-level parks such as pocket parks, may be essential to creating sustainable urban environments that families will desire to live in.

\section{REFERENCES}

1. Ewing, R.R. and R. Cervero. Travel and the built environment: a synthesis. Transportation Research Record, No. 1780, pp. 87-114, 2002.

2. Arnott, R. and M. Kraus. Principles of Transport Economics. Handbook of Transportation Science, R. W. Hall (ed.), $2^{\text {nd }}$ edition. Springer, 2003.

3. Bonner, K. A Great Place to Raise Kids: Interpretation, Science, and the Urban-Rural Debate. McGill-Queen's University Press, Montreal, 1997.

4. Anderson, P.M. and K.F. Butcher. Childhood Obesity: Trends and Potential Causes. Future of Children, Vol. 16, No. 1, spring 2006.

5. Norman, G.J., S.K. Nutter, S. Ryan, J.F. Sallis, K.J. Calfas, and K. Patrick. Community Design and Access to Recreational Facilities as Correlates of Adolescent Physical Activity and Body-Mass Index. Journal of Physical Activity and Health, Suppl. 1, No. 3, 2006, pp. 118-128.

6. "Pilot Program for Childhood Obesity." The Japan Times. November 6 ${ }^{\text {th }}, 2005$.

7. Cutler, D.M., E.L. Glaeser, and J.M. Shapiro. Why Have Americans Become More Obese? Journal of Economic Perspectives, Vol. 17, No. 3, 2003, pp. 93-118.

8. Active Health Kids Canada. Older But Not Wiser Canada's Future At Risk: Canada's Report Card on Physical Activity for Children \& Youth - 2007.

9. Ness, A.R., S.D. Leary, C. Mattocks, S.N. Blair, J.J. Reilly, J. Wells, S. Ingle, K. Tilling, G.D. Smith, and C. Riddoch. Objectively Measured Physical Activity and Fat Mass in a Large Cohort of Children. PLoS Med, Vol. 4, No. 3, 2007.

10. Armstrong, N. Independent mobility and children's physical development. Children, Transport and the Quality of Life, M. Hillman (ed.), London: Policy Studies Institute, 1993, pp. 35-43.

11. Waygood, E.O. and R. Kitamura. Built Environment and Minors' Independent Travel. Paper presented at the TDM 2008 conference, Vienna, Austria, July 16-18, 2008.

12. McDonald, N.C. Children's Travel Patterns: Evidence from the 2001 National Household Travel Survey. TRB 2006 Annual Meeting CD-ROM, 2006.

13. Stefan, K. J. and J. D. Hunt. Age-Based Analysis of Travel by Children in Calgary, Canada. TRB 2006 Annual Meeting CD-ROM, 2006.

14. Sorenson, A. The Making of Urban Japan. Routledge, London, 2002.

15. Hillman, M., J. Adams, and J. Whitelegg. One False Move... A Study of Children's Independent Mobility. Policy Studies Institute, London, 1990.

16. Walking School Bus. www.walkingschoolbus.org, accessed July 22, 2008.

17. Kitamura, R., K. Sakamoto, and O. Waygood. Declining Sustainability: The Case of Shopping Trip Energy Consumption. International Journal of Sustainable Transportation, Vol. 2, No. 3, 2008. 
List of Tables

TABLE 1 Characteristics of the Participating Children and their Neighborhoods TABLE 2 Results of ANOVA Analysis on Main Questions for Weekdays.

TABLE 3 Results of ANOVA Analysis on Main Questions for a Sunday.

List of Figures

FIGURE 1 Example sheet of child-oriented travel diary.

FIGURE 2 Weekday mode split for all trips over four population density groups. FIGURE 3 Mode splits for Sundays.

FIGURE 4 The locations of "running-level" activities for a weekday.

FIGURE 5 The locations of "running-level activities for a Sunday. 


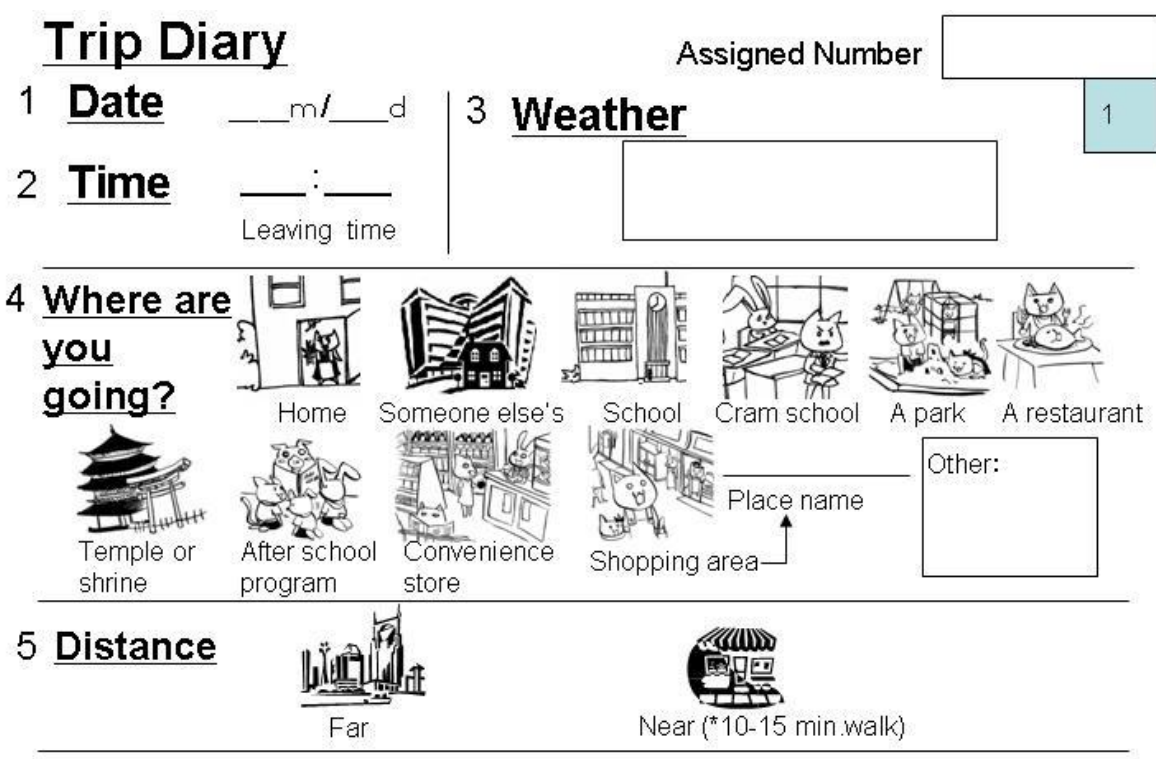

6 How are you going there?

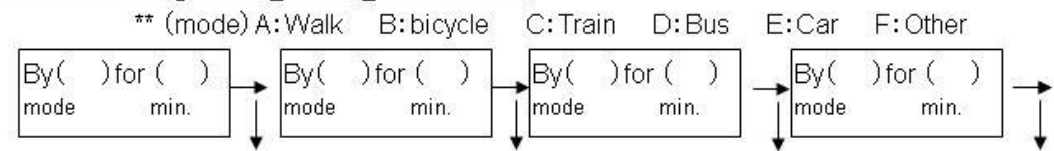

(1) destination (2) destination

(3) destination

(4) destination

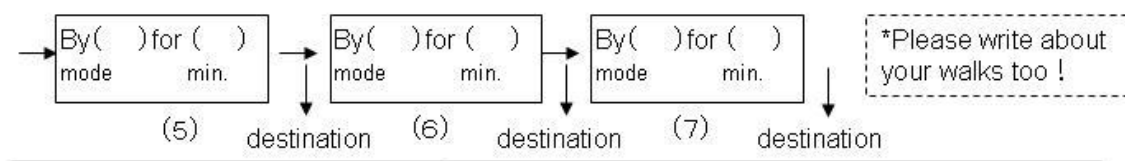

7 Who are
you going
with?
$\begin{array}{lllll}\text { Who did } & \text { Known } \\ \text { you see? } & \text { What did } & \text { Sitting/Standing } \square & \text { Walking } \square & \text { Running } \square \\ \text { you do? } & \text { (e.g. studying) } & \text { (e.g. shopping) } & \text { (e.g. sports, hiking) }\end{array}$

FIGURE 1 Example sheet of child-oriented travel diary. 
TABLE 1 Characteristics of the Participating Children and their Neighborhoods

\begin{tabular}{|l|c|c|c|c|c|c|}
\hline $\begin{array}{l}\text { Population Density } \\
\text { Group }\end{array}$ & $\begin{array}{c}\text { Population } \\
\text { Density* }\end{array}$ & $\begin{array}{c}\text { Service } \\
\text { Density* }\end{array}$ & Boys & $\begin{array}{c}\text { Household Car } \\
\text { Ownership }\end{array}$ & $\begin{array}{c}\text { Buses per } \\
\text { day* }\end{array}$ & $\begin{array}{c}\text { Train } \\
\text { Stations }\end{array}$ \\
\hline $\begin{array}{l}\text { less than } 2000 \\
\text { (n=37) }\end{array}$ & 577 & 13.2 & $51 \%$ & 1.89 & 40 & 0 \\
\hline $\begin{array}{l}2000 \text { up to } 3999 \\
\text { (n=36) }\end{array}$ & 2363 & 22.4 & $64 \%$ & 1.44 & 90 & 0.1 \\
\hline $\begin{array}{l}4000 \text { up to } 6499 \\
\text { (n=144) }\end{array}$ & 6050 & 74.3 & $45 \%$ & 1.22 & 12 & 1.2 \\
\hline $\begin{array}{l}6500 \text { and above } \\
(n=115)\end{array}$ & 10218 & 120.3 & $46 \%$ & 0.94 & 64 & 1.2 \\
\hline
\end{tabular}

*Values are for child's neighborhood which is defined as a $1 \mathrm{~km}(0.62 \mathrm{mile})$ square around the center of their postal code. (Less than 5180 people/m²; 5180 to $10357 \mathrm{people} / \mathrm{m}^{2} ; 10360$ to 16832 people/m²; 16835 people $/ \mathrm{m}^{2}$ and up) 


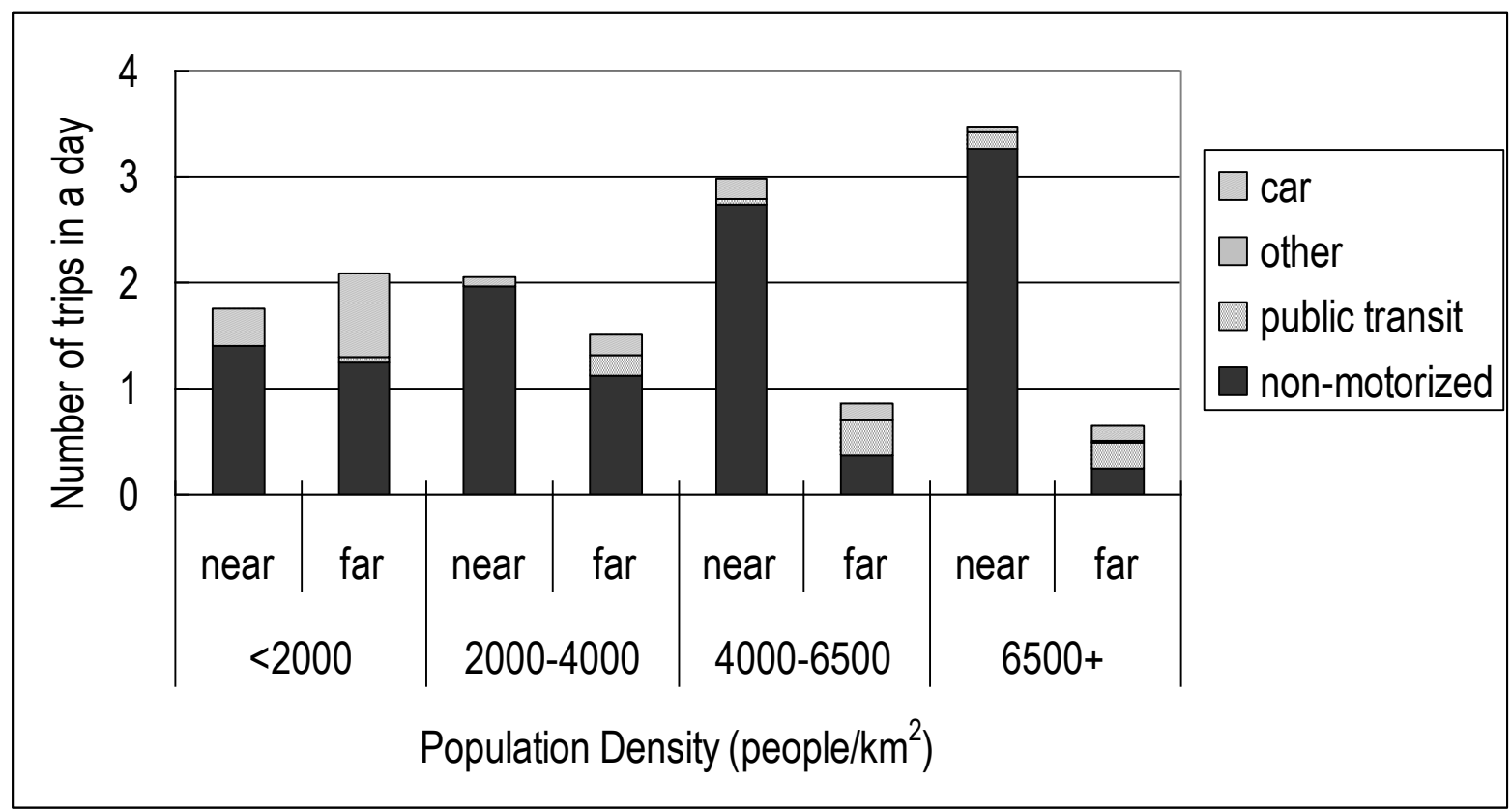

FIGURE 2 Weekday mode split for all trips over four population density groups. A trip was far if the child felt that they could not walk to the destination in about 15 minutes. $(N=36,34,112$, and 82 respectively). 


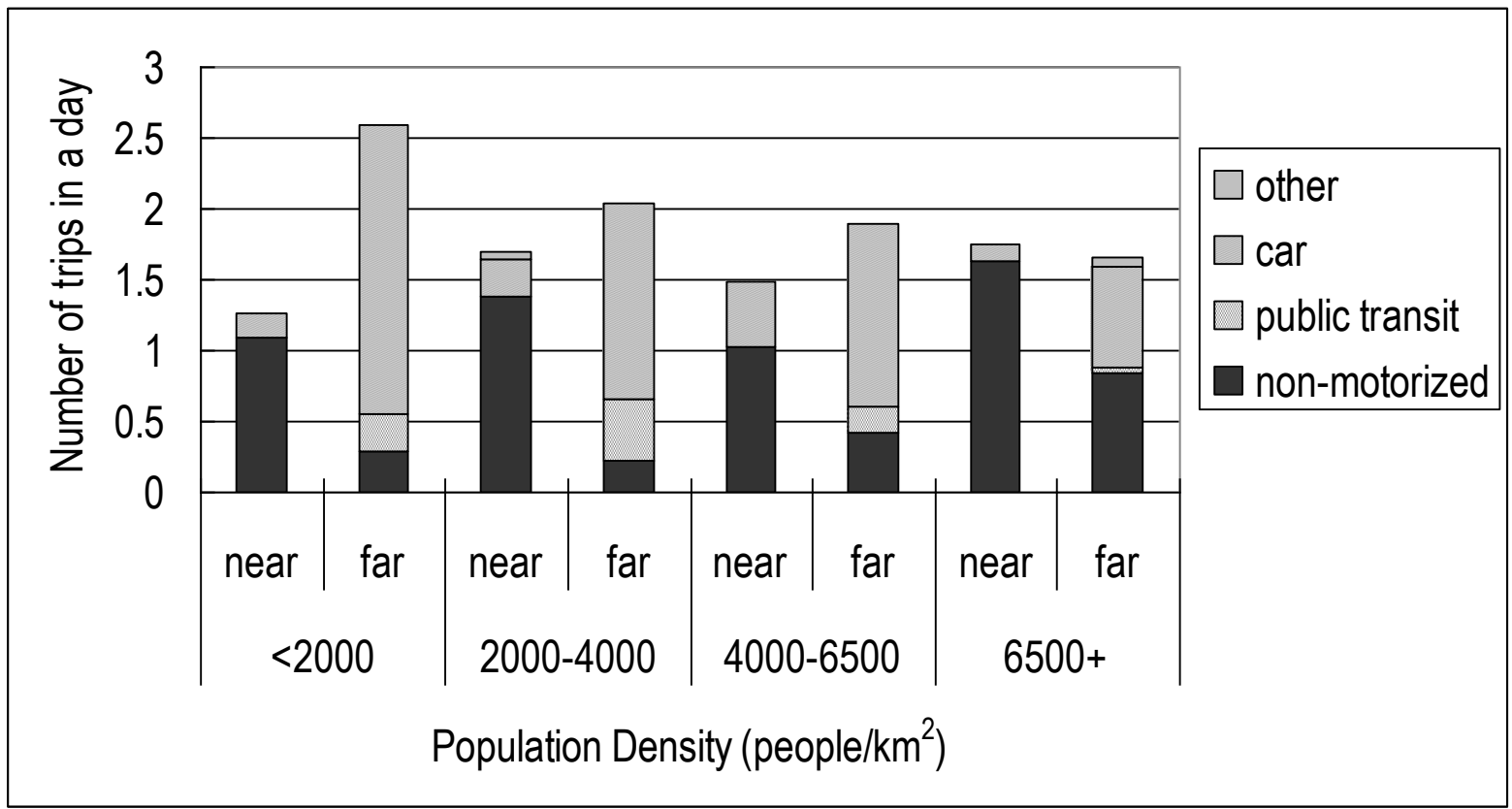

FIGURE 3 Mode splits for Sundays. A trip was marked as far if the child felt that they could not walk to it in about 15 minutes. $(N=34,37,87$, and 44 respectively). 
TABLE 2 Results of ANOVA Analysis on Main Questions for Weekdays.

\begin{tabular}{|c|c|c|c|c|c|c|c|c|}
\hline & \multicolumn{4}{|c|}{ Population Density } & & & & \multirow[b]{2}{*}{$\begin{array}{l}\text { Correlation } \\
\text { Coefficient }\end{array}$} \\
\hline & $\begin{array}{l}\mathrm{LOW}^{*} \\
(\mathrm{~N}=37) \\
\end{array}$ & \begin{tabular}{|l|} 
Medium** \\
$(\mathrm{N}=34)$
\end{tabular} & \begin{tabular}{|l} 
High $^{*}$ \\
$(\mathrm{~N}=112)$ \\
\end{tabular} & $\begin{array}{l}\text { Very High* } \\
(\mathrm{N}=82)\end{array}$ & $\begin{array}{l}\text { Sum of } \\
\text { Squares }\end{array}$ & $\begin{array}{l}\text { Mean } \\
\text { Square }\end{array}$ & F-ratio & \\
\hline & \begin{tabular}{|l} 
Value \\
(Std. Err.)
\end{tabular} & \begin{tabular}{|l} 
Value \\
(Std. Err.)
\end{tabular} & $\begin{array}{l}\text { Value } \\
\text { (Std. Err.) }\end{array}$ & $\begin{array}{l}\text { Value } \\
\text { (Std. Err.) }\end{array}$ & & & DF $(4,261)$ & \\
\hline $\begin{array}{l}\text { Known person } \\
\text { seen on trip } \\
(\% \text { of all }\end{array}$ & $\begin{array}{c}64.3 \% \\
(5 \%)\end{array}$ & $\begin{array}{l}74.0 \% \\
(5.3 \%)\end{array}$ & $\begin{array}{l}67.7 \% \\
(2.9 \%)\end{array}$ & $\begin{array}{l}78.3 \% \\
(3.4 \%)\end{array}$ & 135.5 & 33.9 & 359.6 & 0.135 \\
\hline $\begin{array}{l}\text { Independent } \\
\text { Trips (\% of all } \\
\text { trips/day) }\end{array}$ & $\begin{array}{l}58.3 \% \\
(3.8 \%)\end{array}$ & $\begin{array}{l}86.7 \% \\
(3.9 \%)\end{array}$ & $\begin{array}{l}88.5 \% \\
(2.2 \%)\end{array}$ & $\begin{array}{l}90.8 \% \\
(2.5 \%)\end{array}$ & 193.6 & 48.4 & 920.4 & 0.369 \\
\hline $\begin{array}{l}\text { Running-level } \\
\text { Activity } \\
\text { (times/day) }\end{array}$ & $1.54(.24)$ & $1.27(.25)$ & $1.38(.14)$ & $1.02(.16)$ & 442.8 & 110.7 & 54.1 & -0.061 \\
\hline \multirow[t]{2}{*}{$\begin{array}{l}\text { Exercise } \\
\text { through travel } \\
\text { (min./day) }\end{array}$} & $\begin{array}{c}40.6 \\
(3.97)\end{array}$ & $43.7(4.14)$ & $33.6(2.28)$ & $27.3(2.66)$ & 313135.4 & 78283.9 & 134.6 & -0.15 \\
\hline & $(\mathrm{N}=148)$ & $(\mathrm{N}=123)$ & $(\mathrm{N}=468)$ & $(\mathrm{N}=274)$ & & \multicolumn{3}{|c|}{$\mathrm{DF}(4,1009)$} \\
\hline $\begin{array}{l}\text { Avg. Trip time } \\
\text { (min./trip) }\end{array}$ & $\begin{array}{c}13.41 \\
(.77)\end{array}$ & $13.59(.85)$ & $8.64(.44)$ & $8.89(.57)$ & 105968.4 & 26492.1 & 299.5 & -0.233 \\
\hline
\end{tabular}

Significant at $p<0.001$ for all dependent variables

* "Low" is less than 2000 people/km², "medium" is from 2000 to up to 3999 people/km², "high" is from 4000 up 6499 people/km², and "very high" is from 6500 people/km² and above. 
TABLE 3 Results of ANOVA Analysis on Main Questions for a Sunday.

\begin{tabular}{|c|c|c|c|c|c|c|c|c|}
\hline & \multicolumn{4}{|c|}{ Population Density } & \multirow[b]{2}{*}{$\begin{array}{l}\text { Sum of } \\
\text { Squares }\end{array}$} & \multirow[b]{2}{*}{$\begin{array}{l}\text { Mean } \\
\text { Square }\end{array}$} & \multirow[b]{2}{*}{ F-ratio } & \multirow[b]{2}{*}{$\begin{array}{l}\text { Correlation } \\
\text { Coefficient }\end{array}$} \\
\hline & $\begin{array}{l}\text { Low }^{*} \\
(\mathrm{~N}=37)\end{array}$ & $\begin{array}{c}\text { Medium* } \\
(\mathrm{N}=34)\end{array}$ & $\begin{array}{l}\text { High* }^{*} \\
(\mathrm{~N}=112)\end{array}$ & $\begin{array}{l}\text { Very High* } \\
(\mathrm{N}=82)\end{array}$ & & & & \\
\hline & $\begin{array}{c}\text { Value (Std. } \\
\text { Err.) }\end{array}$ & $\begin{array}{l}\text { Value (Std. } \\
\text { Err.) }\end{array}$ & $\begin{array}{c}\text { Value (Std. } \\
\text { Err.) }\end{array}$ & $\begin{array}{c}\text { Value (Std. } \\
\text { Err.) }\end{array}$ & & & DF $(4,198)$ & \\
\hline 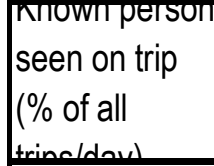 & $\begin{array}{l}41.7 \% \\
(6.7 \%)\end{array}$ & $\begin{array}{l}42.2 \% \\
(6.4 \%)\end{array}$ & $\begin{array}{l}37.3 \% \\
(4.2 \%)\end{array}$ & $\begin{array}{l}61.3 \% \\
(5.8 \%)\end{array}$ & 41.1 & 10.3 & 68.3 & 0.126 \\
\hline $\begin{array}{l}\text { Independent } \\
\text { Trips (\% of all } \\
\text { trips/day) }\end{array}$ & $\begin{array}{l}23.9 \% \\
(6.9 \%)\end{array}$ & $\begin{array}{l}24.5 \% \\
(6.6 \%)\end{array}$ & $\begin{array}{l}30.4 \% \\
(4.3 \%)\end{array}$ & $\begin{array}{c}53.9 \% \\
(6.1)\end{array}$ & 25 & 6.25 & 38.9 & 0.226 \\
\hline $\begin{array}{l}\text { Running-level } \\
\text { Activity } \\
\text { (times/day) }\end{array}$ & $1.44(.20)$ & $.84(.19)$ & $.75(.13)$ & $1.05(.18)$ & 193.2 & 48.3 & 34.7 & -0.106 \\
\hline $\begin{array}{l}\text { Exercise } \\
\text { through travel } \\
\text { (min/dav) }\end{array}$ & $11.5(4.5)$ & $15.7(4.3)$ & $19.6(2.8)$ & $23.7(3.9)$ & 71772 & 17943 & 26.3 & 0.153 \\
\hline & $(N=134)$ & $(\mathrm{N}=137)$ & $(\mathrm{N}=327)$ & $(\mathrm{N}=159)$ & & & DF $(4,753)$ & \\
\hline $\begin{array}{l}\text { Avg. Trip time } \\
\text { (min./trip) }\end{array}$ & $\begin{array}{l}20.42 \\
(2.31)\end{array}$ & $\begin{array}{l}21.03 \\
(2.29)\end{array}$ & $\begin{array}{l}20.08 \\
(1.48)\end{array}$ & $\begin{array}{l}15.34 \\
(2.12)\end{array}$ & 285719.7 & 71419.9 & 99.9 & -0.142 \\
\hline
\end{tabular}

Significant at $p<0.001$ for all dependent variables.

* "Low" is less than 2000 people/km², "medium" is from 2000 to up to 3999 people/km², "high" is from 4000 up 6499 people/km², and "very high" is from 6500 people $/ \mathrm{km}^{2}$ and above. 


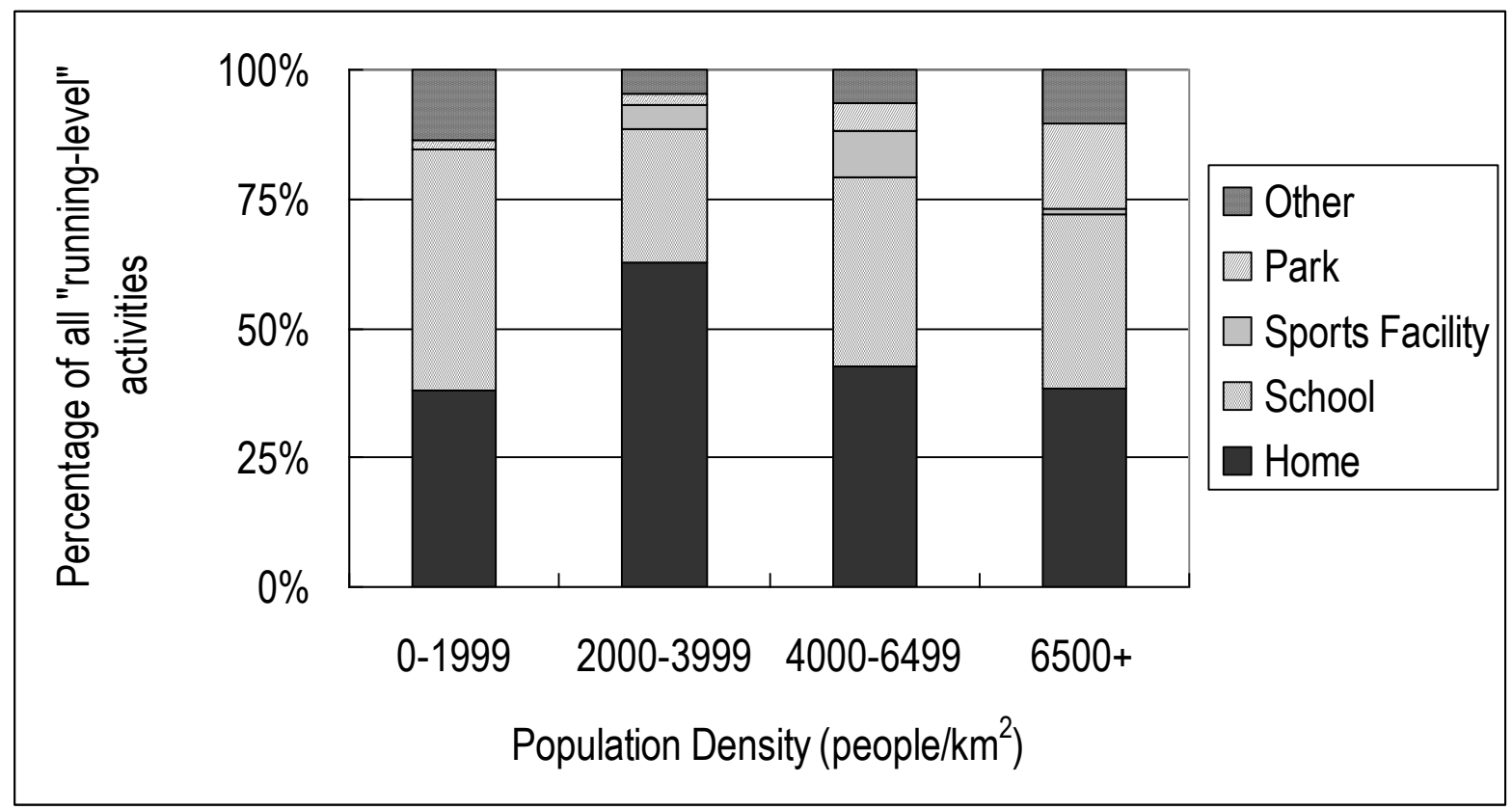

FIGURE 4 The locations of "running-level" activities for a weekday. $(\mathrm{N}=57,43,153$, and 87 respectively). 


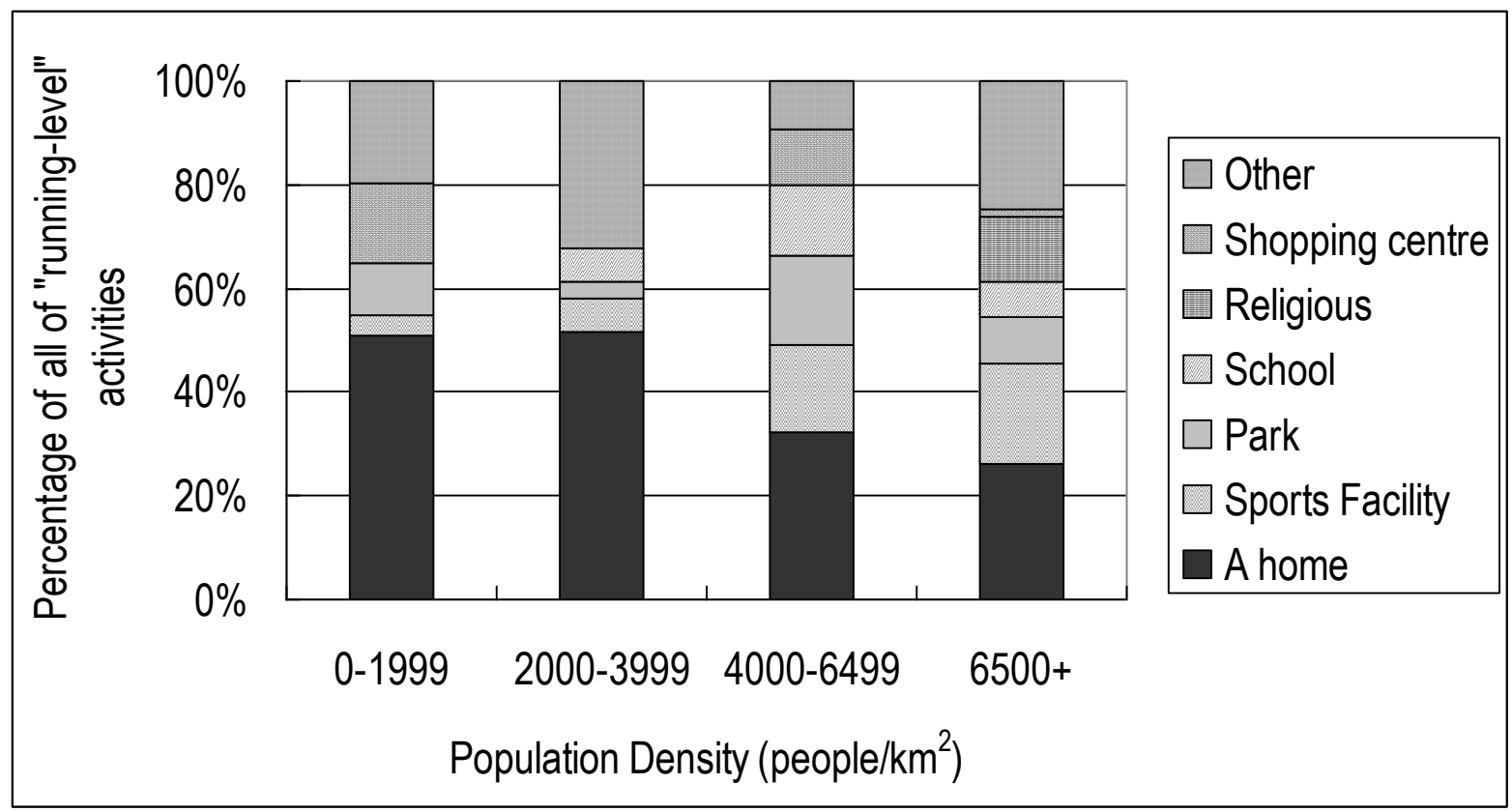

FIGURE 5 The locations of "running-level activities for a Sunday. $(\mathrm{N}=51,31,65$, and 57 respectively). 